ceptibility to irradiation have not been adequately confirmed ${ }^{5}$. Studies of differences in red cell membranes by electron spin resonance and of $a b$ normalities in $\left(\mathrm{Na}^{+}+\mathrm{K}^{+}\right)$ATPase have not been replicated ${ }^{6,7}$. To date one cannot point to any described abnormality of other cells which provides an indication or marker of the genetic defects.

Perhaps the answer will ultimately come from the new techniques of molecular genetics. The Huntington's disease gene is considered to have a penetrance of 100 per cent and the mutation rate is exceedingly low; indeed, no proven cases of sporadic mutation have ever been described which satisfy the criteria of proven parentage, with parents surviving to an old age without symptoms, pathologically proven Huntington's disease in the new case, and subsequent transmission to a child. The low mutation rate makes it possible and practicable to search for a DNA polymorphism which might be useful as a genetic linkage marker ${ }^{8}$. So far the chromosomal localization of the defect is unknown but restriction endonuclease digests of DNA collected from the peripheral white blood cells of patients with the disease, combined with somatic cell hybridization, are being used to localize the polymorphisms to a specific chromosome. In the long term, it should be possible to survey each chromosome in the human genome sequentially, first for a polymorphism to provide a genetic linkage and ultimately to localize the gene itself. There will then be a real possibility of identifying the metabolic defect.

1. Bird, E.D. A. Rev. Pharmac. Tox. 20, 511 (1980).

2. Coyle, J.T. \& Schwarcz, R. Nature 263, 244 (1976).

3. Ferkany, J.W., Zaczek, R. \& Coyle J.T. Nature 298 757 (1982)

4. Berger, M., Sperk, G. \& Hornykiewicz, O. Nature 299, 254 (1982)

5. Goetz, J.E., Roberts, E. \& Warren, J. Am. J. Hum. Genet. 33, 187 (1981).

6. Fung, L.W.M. \& Ostrowski, M.S. Am. J. Hum. Genet 34,469 (1982).

Comings, D.E., Pekkala, A., Schuh, J.R., Kuo, P.C \& Chan, S.I. Am. J. Hum. Genet. 33, 166 (1981).

8. Houseman, D.E. \& Gusella, J.F. Molecular Genetic Neuroscience (eds Schmitt, F.O., Bird, S.J. \& Bloom, F.E.) 415-424 (Raven, New York, 1982).

\title{
Rapid environmental and climatic changes
}

\section{from D. Q. Bowen}

THE successful characterization and evaluation of past rapid changes in the environment and climate depend largely on the integrity and sensitivity of dating methods. All too of ten imprecision in the climatic record stems from dating uncertainties, with bioturbation and a variety of lag effects providing additional problems. Given these constraints, it is little wonder that much of a recent meeting* on the character and timing of rapid environmental and climatic changes was devoted to the comparatively well-dated Holocene record and, to a lesser extent, to that of the later part of the last glaciation. Small-scale systems of generally short duration, but for which detailed data were available, received far more attention than the larger systems with somewhat coarser data available over longer time scales.

At the larger end of the scale it is difficult to identify specific climatic causes for changes in climate (R.V. Barry, University of Colorado, Boulder). Among the many uncertainties are whether fluctuations on the 100-1,000 year scale are due to longitudinal and/or latitudinal changes in circulation; whether particular regimes persist for long periods and what the circulation

- The 7th Biennial Conference of the American Quaternary Association on 'Character and Timing of Rapid Environmenta and Climatic Changes' was held at the University of Washington, Seattle, 28-30 June 1982 .

D. Q. Bowen is in the Department of Geography, The University College of Wales, Aberystwyth $S Y 233 D B$. variability of different regimes is. It is not even possible to ascribe the quasi-persistent types of circulation regime to external or internal forcings, to atmospheric autovariation or to internal feedback mechanisms between land, ocean and atmosphere. Barry stressed, however, that the intensity and timing of climatic change will show considerable geographical variation: step-like in some areas but more gradual in others.

R. Bryson (University of Wisconsin, Madison) further stressed that in regarding climatic change as essentially nonlinear, a major break with tradition had now occurred; while J. Mitchell (Environmental Data Service, Silver Spring, Maryland) emphasized the role of the oceans as a global climatic fly-wheel which limits change more strictly over shorter than over longer periods. Deep water formation in the North Atlantic may also play an important part in speeding glacial events; sea-level changes can lead to perturbations in oceanic thermocline circulation processes which may enhance oceanic heat transportation to higher latitudes during periods of glacial growth (C. Rooth, University of Miami).

Global data show considerable glacial fluctuations during the last glaciation, mostly reflecting local or anomalous conditions (S. Porter, University of Washington, Seattle) and the glacier response to rapid climatic change is best assessed from Holocene examples where lead and lag effects can be partially quantified. Sea-level data for the past 140 kyr (T. Cronin, US Geological Survey, Reston) demonstrate the many pressing problems still extant: where was the last glacial maximum sea level? Where was sea level during the mid-Wisconsin? How rapid were sea-level changes? The possibility of a high sea-level event between 130 and 140 kyr received much attention but was strongly questioned by W.Ruddiman (National Science Foundation) on the basis of the oxygen- 18 record.

The most sensitive indications of climatic change are provided by the oxygen-18 record in ice sheets followed by sea-surface temperatures $(H$. Wright, University of Minnesota, Minneapolis). Most pollen records are beset by persistent difficulties in interpretation due to their proximity to ice sheets. Sensitivity and response times might thus be better detected at very low latitudes or in the Southern Hemisphere, free from such influences. Furthermore the climatic signal from pollen data fails to provide a clear record of climatic change of short duration even when its amplitude is large (M. Davis, University of Minnesota): for example, the 'Little Ice Age' is only recorded clearly by pollen at a few sites, despite the considerable impact on human culture. Except in a few cases it is difficult to infer from pollen data whether climatic change is stepwise or gradual and unidirectional (W. Watts, Trinity College Dublin). Relationships between climatic change and the pollen record are only indirect because plant populations generally become established long after causal climatic events. There is thus an urgent need to identify sensitive ecotonal areas at the margins of plant ranges where pollen data and climate can be linked directly. Most rapid of all may be the response of lake sediments to climatic change (R. Anderson, University of New Mexico, Albuquerque). Seasonal control is dominant and gives a clear signature, while cumulative changes in seasonal components demonstrate rapid climatic change. It should be possible to design transfer functions expressing linkages between climate and sedimentation, with eventual application to non-varied sediments.

In summing up the proceedings, J. Mitchell predicted that climate will change over a transitional period of the next 200 years because of an increased carbon dioxide content in the atmosphere, then settle into a 1,000 year equilibrium state. The rapidity of this transition could be comparable to that at the Younger Dryas to Holocene change some 10,000 years ago. $\square$

Erratum
In K.F. Chater's article 'Streptomyces in
the ascendant' (News and Views 299, 10; 2
September 1982), the last eleven lines of
paragraph four (beginning 'As a result,
.. .') should have appeared at the end of
paragraph five.

